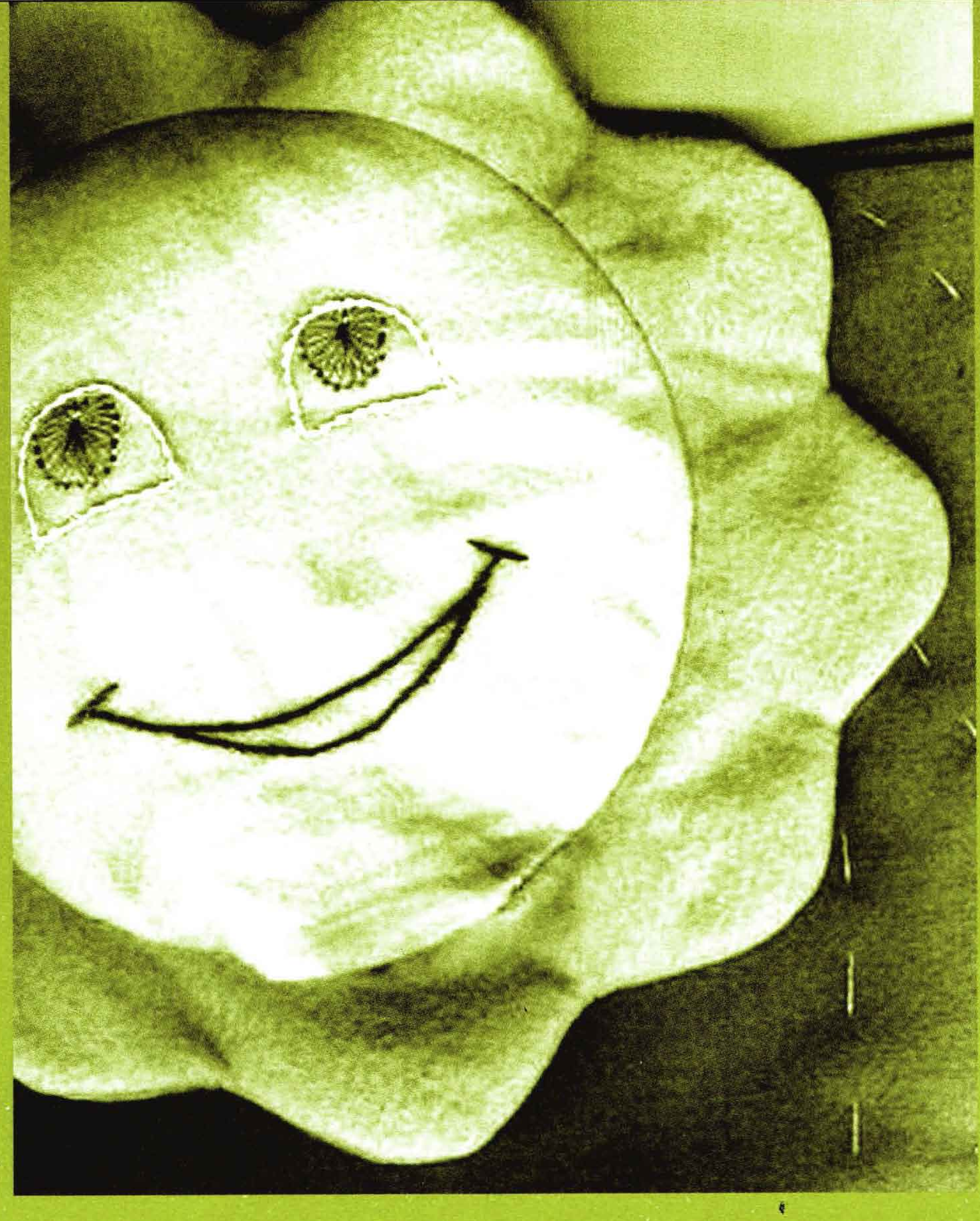

\title{
Ciudad Educadora discursos y prácticas
}




\section{Olga Cecilia Díaz}

Psicolóloga, Universidad Católica de Colombia, Bogotá. Maestría en Desarrollo Educativo y Social. Universidad Pedagógica Nacional - Centro Internacional de Educación y Desarrollo Humano - CINDE. Becaria del Curso de Formación de Analistas de Políticas Educativas. Beca por concurso REDUC - BID. Universidad Católica de Córdoba. Argentina. Invitación a participar con la conferencia "La educación especial y la integración educativa en América Latina". Secretaria de Educación Básica y Normal. Coordinadora de grupos de maestros del sector público participantes en la Cátedra de Pedagogía "Bogotá: Una Gran Escuela".IDEP, 2005.

\section{Resumen}

Este artículo identifica concepciones, orientaciones y efectos diferenciables, tanto desde los discursos como desde las experiencias internacionales y nacionales sobre Ciudad Educadora, y ubica tres tendencias discursivas que se materializan en diversas modalidades de práctica, las cuales se orientan a promover tres concepciones de la educación y la pedagogía y que le atribuyen lugares distintos al maestro y a la escuela: la Ciudad Educadora como escuela para la sociedad, como escuela para la inclusión y la humanización, o como escuela del sujeto. Finalmente se destacan visiones diferenciables que promueven sentidos distintos dentro de una aparente coincidencia discursiva.

\section{Palabras clave} sujeto.

Ciudad Educadora, tendencias discursiva, concepciones, pedagogía, escuela, inclusión, humanización,

\section{Abstract}

This article identifies some concepts, directions, and differential effects of the discourse and the international experiences of Educating Cities. It establishes three broad discourse trends that materialize in diverse practice modes which try to promote three different ideas of education and pedagogy that produce different places for the school and the teacher to occupy: the Educating City as a school for society, as a school for humanization and inclusion, and as a school for the subject. The article enhances the fact that different meanings exist amidst an apparently similar discourse.

\section{Key words}

Educating City, discourse trend, pedagogy, school, inclusion, humanization, subject. 


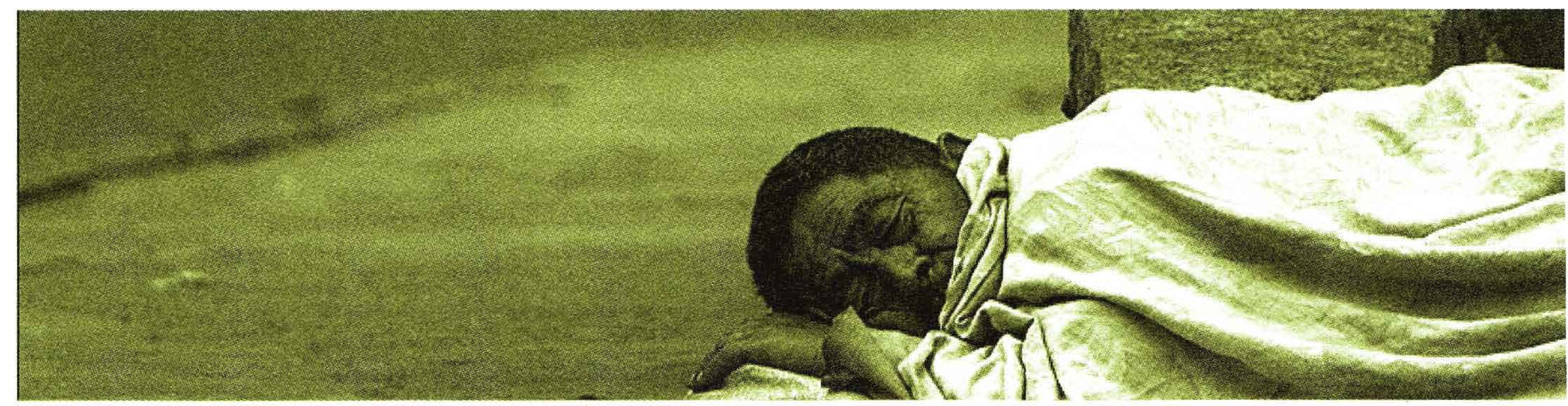

$\mathbb{E}$ $\mathrm{n}$ un intento por generar distinciones que nos permitan ubicar las implicaciones de la propuesta de Ciudad Educadora, en y para los contextos y sujetos participantes en este proceso de la Cátedra de Pedagogía, consideramos conveniente identificar conceptos, orientaciones y efectos diferenciados, tanto desde los discursos como desde las experiencias internacionales y nacionales presentadas en este escenario formativo.

Desde esta perspectiva, ubicamos tres tendencias discursivas que se materializan en diversas modalidades de práctica, los cuales se orientan a promover tres conceptos diferentes de la educación y la pedagogía, y que le atribuyen lugares distintos al maestro y a la escuela. Dichas tendencias son: la Ciudad Educadora como escuela para la sociedad, la Ciudad Educadora como escuela para la inclusión y la humanización, la Ciudad Educadora como escuela del sujeto $^{2}$. Es de aclarar que no optamos

2 En algunas de estas denominaciones, estamos inspirados en los planteamientos que hace Touraine. ¿Podremos vivir juntos? El destino del hombre en la aldea global. Buenos Aires, Fondo de Cultura Económica, 1998. Capítulo "La Escuela del Sujeto". por una lectura purista de los enunciados; en tal sentido, en las propuestas que retomamos entendemos la coexistencia de perspectivas, la hibridación e, incluso, la incoherencia. No obstante, también es posible destacar visiones diferenciadas que promuevan sentidos distintos, dentro de una aparente coincidencia discursiva ${ }^{3}$.

\section{La Ciudad Educadora como escuela para la sociedad}

En este concepto, ubicamos aquellas orientaciones en las que se plantea que la relación escuela-ciudad se inscribe en una educación centrada en la cultura y los valores de una sociedad en la que se privilegia la idea de escuela como agente de socialización. Es decir, centradas en el aprendizaje de roles sociales.

Desde este punto de vista, la escuela y el maestro se conciben como transmisores de un conjunto de conocimientos, normas, valores y representaciones, que

3 La Carta de Ciudades Educadoras podría ser vista, en tanto discurso universalista, como expresión de la primera perspectiva. Sin embargo, en muchos de sus enunciados se percibe la tensión entre los tres enfoques de ciudad educadora, aquí bosquejados. 


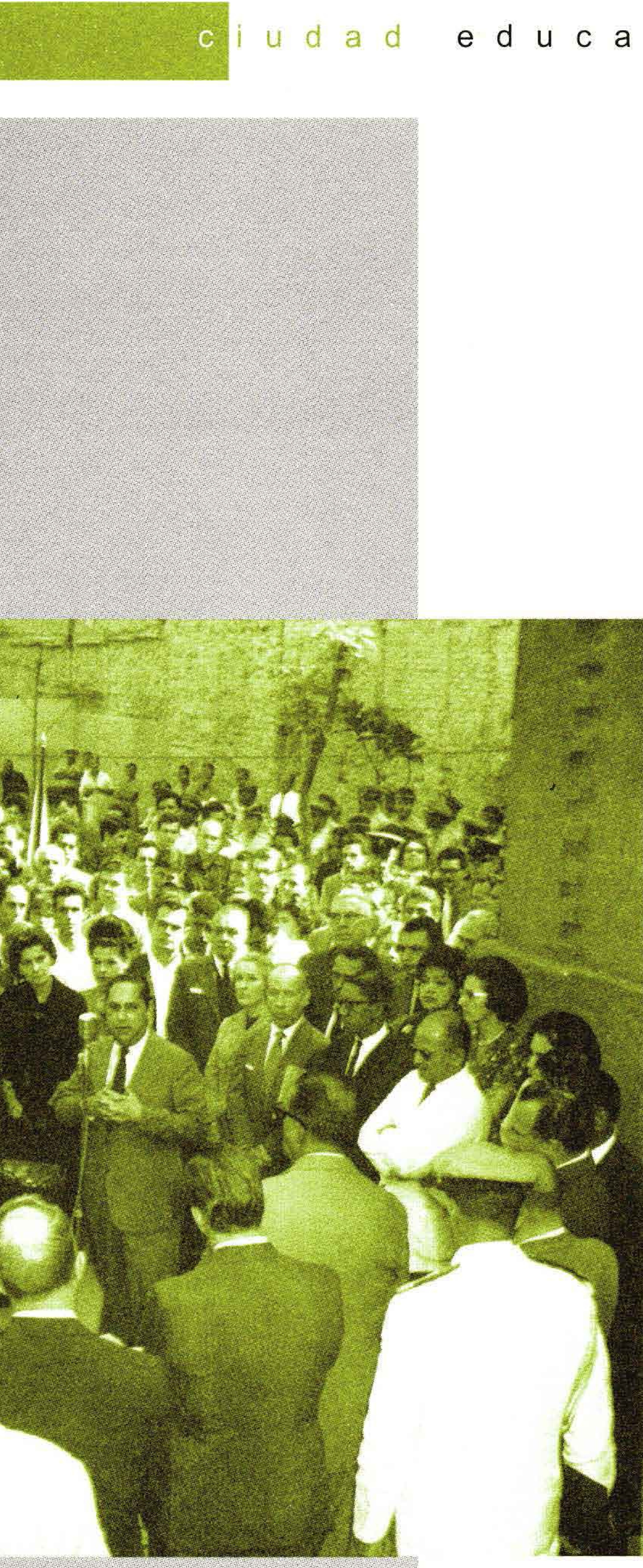

aun cuando amplían el sentido de ciudadanía y participación en los nuevos escenarios que ofrece la ciudad, no interpelan el sentido del proyecto social en juego ni el papel de la educación; ésta sigue orientada a demandar la apropiación de conocimientos y valores, el desarrollo de habilidades y/o destrezas que pretenden hacer idóneo al hombre para una sociedad del trabajo y la productividad. Así, la educación no se centra en el individuo sino en la sociedad.

Se podría señalar, entonces, que las tres versiones de Ciudad Educadora planteadas por Trilla y retomadas en la Carta de Ciudades Educadoras -la ciudad como entorno o contenedor de recursos educativos (aprender EN la ciudad). La ciudad como agente educativo (aprender DE la ciudad). Y la ciudad como contenido u objetivo educativo (aprender LA ciudad)- ilustran en buena medida este concepto.

De forma semejante, enunciados como "la escuela puede y debe desarrollar un papel-compartido pero remarcable - en la formación en valores, en la educación de la ciudadanía o en la reconstrucción de la sociedad civil", o "la escuela está para enseñar lo que no puede aprenderse directamente", o incluso el principio de la permeabilidad selectiva propuesto por Trilla serían planteamientos que aludirían a esta forma de entender la idea de escuela para la sociedad.

Dada la visión compartida de varios de los conferencistas invitados, debemos ubicar igualmente los planteamientos de Pilar Figueras y de Alicia Cabezudo en sus ponencias magistrales. La primera de ellas señalaba que "la ciudad es educado- 
ra cuando imprime esta intencionalidad en el modo como se presenta a sus ciudadanos, consciente de que muchas de las propuestas conllevan a aprendizajes, tienen consecuencias 'actitudinales' y 'convivenciales', y generan nuevos valores, conocimientos y destrezas". También destacaba que "la escuela debe ser conocedora y apreciadora de la ciudad física, de sus lugares y de la significación que éstos tienen, puesto que todo ello conforma nuestras identidades de la ciudad cultural y medioambiental, de su historia y tradiciones. En la escuela, la educación en valores, que ha de formar a niños y jóvenes cívicos y responsables, ha de impregnar la forma de vida de toda la escuela".

El énfasis de la perspectiva universalista de los derechos humanos planteada por la segunda expositora mencionada, Alicia Cabezudo, igualmente daría lugar a ubicarla en este primer enfoque.

A su vez, en los enunciados de Vito Alessio Álvarez aparece la dimensión tal vez más instrumental y utilitarista de este concepto, cuando señala que "utilizar la ciudad para fines didácticos, convertirla en una fuente y en un medio de prácticas educativas e intervenciones pedagógicas de todo tipo -encaminadas a ayudar a que nuestros niños y jóvenes adquieran conciencia de la realidad de su vida, dentro del marco de su cotidianidad-y ofrecerles medios para desarrollar su sentido de pertenencia a su ambiente y su amor por su ciudad, es y seguirá siendo la forma más eficaz de satisfacer las necesidades educativas de los ciudadanos".

Propuestas que se ratifica cuando se sustenta la manera como en Ciudad Victoria se promovió la propuesta de Ciudad Educadora, pues ésta surge ante la preocupación por el deterioro notable de las diversas culturas en la sociedad victorense, y por el crecimiento alarmante de la inseguridad, la ilegalidad y la corrupción, principalmente; 'desculturización' que día a día se manifiesta en forma más ostensible y evidente, y que hace que las conductas, valores y principios que la escuela con tanta dificultad siembra en los niños y jóvenes no puedan ser reafirmados en el hogar y en la sociedad.

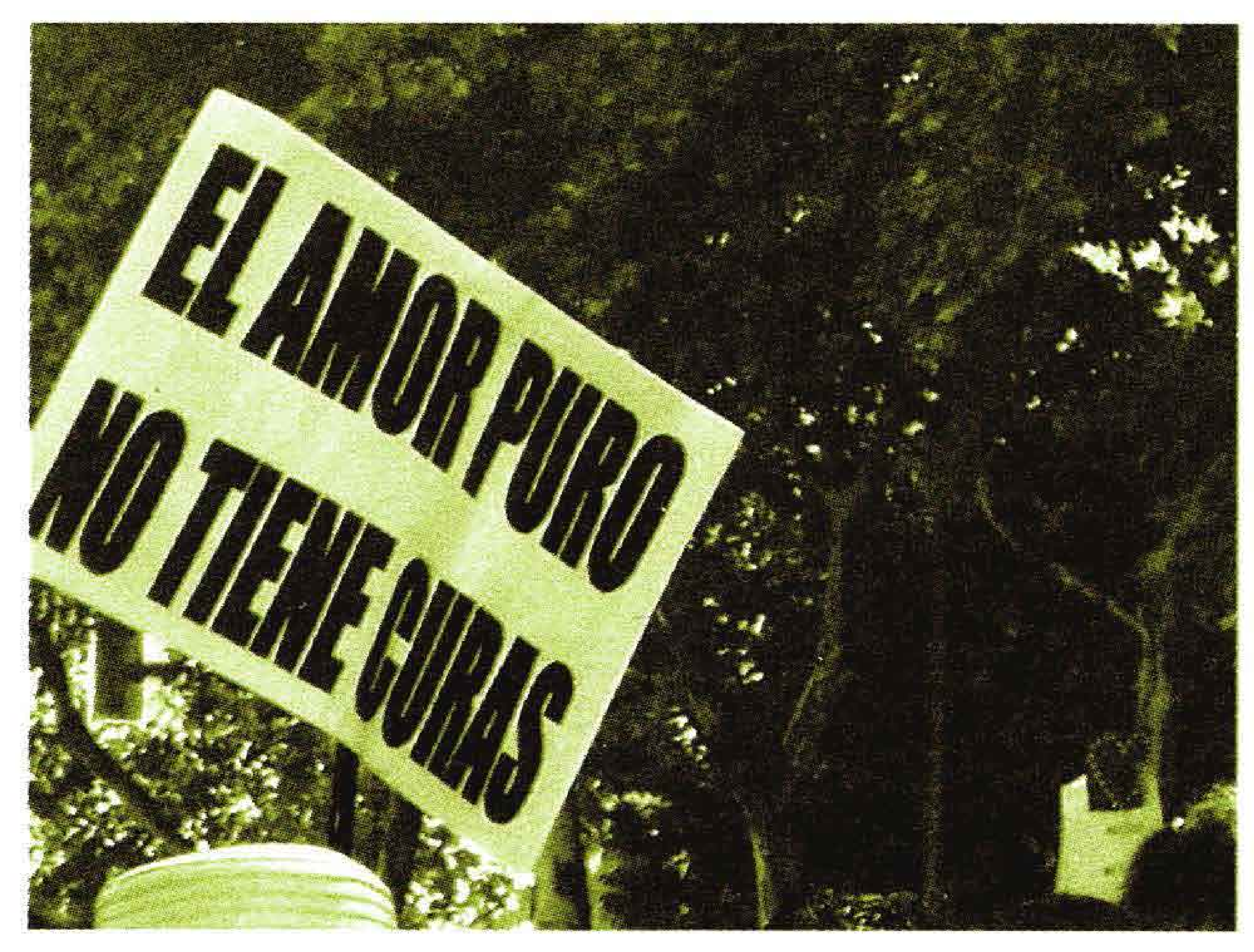




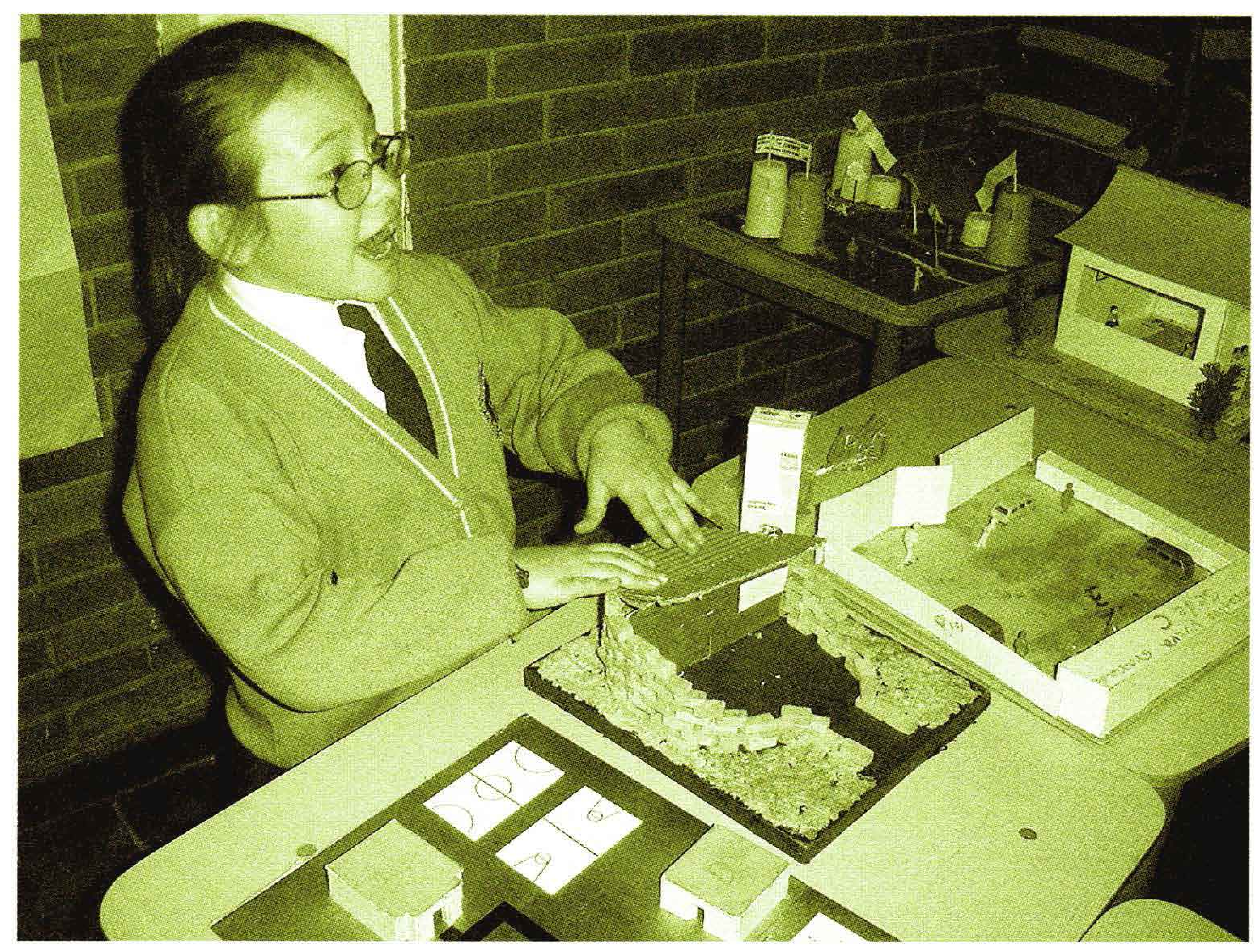

\section{La Ciudad Educadora como escuela para la inclusión y la humanización}

Aunque la anterior orientación y ésta comparten el énfasis en proyectarse hacia los ideales de la modernidad, consideramos que el carácter político-pedagógico que se formula desde esta comprensión de Ciudad Educadora da lugar a ubicarla dentro de otro enfoque.

Así, se establece una relación directa entre pedagogía crítica y construcción de la subjetividad democrática, en la que la desigualdad no es una cuestión natural, como tampoco es neutral el proceso educativo, ya que éste siempre está permeado por una ideología determinada. De esta manera, se hace explícito el carácter político de la educación. La ciudad y la escuela se convierten, por tanto, en escena- rios y objetos de crítica, en los que a través de acciones de concientización se busca que los oprimidos generen cambios y actúen para transformar su situación. La educación se reconoce, así, como una acción liberadora.

En esta manera de plantearse la Ciudad Educadora, ésta se ve ligada a la escuela ciudadana. Como lo destaca Gadotti, "no se puede hablar de escuela ciudadana sin comprenderla como escuela participativa, apropiada por la población como parte de la apropiación de la ciudad a la que pertenece". En este sentido, la escuela ciudadana, en mayor o en menor grado, supone la existencia de una Ciudad Educadora; apropiación que se da a través de mecanismos creados por la escuela, como el colegiado escolar, la constituyente escolar, las plenarias pedagógicas y otros. Por tanto, escuela ciudadana y Ciudad Educadora se asumen como movimientos 
que tienen la misma identidad y que apuntan hacia el mismo proyecto a futuro: la construcción de una sociedad 'educadora-educanda', humanizada, emancipada y solidaria. Ese es el escenario de una ciudad que educa, en el cual las prácticas escolares posibilitan cualificar el entendimiento freireano tanto de la lectura de la palabra escrita como de la lectura del mundo. "La ciudad que educa no se queda en lo inmediato, sino que apunta a una comprensión analítica y reflexiva de los problemas cotidianos y de los desafios del mundo contemporáneo", nos aclara Gadotti.

La experiencia de Sao Paulo (Brasil) presentada por Maria Aparecida, se ubica justamente dentro de esta perspectiva. Uno de los ejemplos ilustrativos son los Centros Educacionales Unificados -CEU-, asumidos como "un proyecto de educación popular, de educación ciudadana, preocupado por tratar al pueblo con dignidad y respeto", cuya idea fundamental es fortalecer la escuela pública al asociarla con el desarrollo comunitario, a través de su ubicación en las áreas periféricas más pobres de la ciudad. Los CEU se inspiran en el concepto de equipamiento urbano, que agrupa a la comunidad con una visión de educación que trasciende la sala de clase o el espacio escolar.

El CEU, según Gadotti, es un espacio de educación inclusiva, de formación permanente y de humanización de las relaciones sociales. Es público en cuanto a su destinación; democrático y comunitario en cuanto a su gestión, y estatal en cuanto a su financiamiento. La elaboración de su proyecto educacional implica la construcción de un proceso que per- mite la actualización de sus propias experiencias y contextos, y reconoce, convive y trabaja con las diferencias. El CEU, concebido en la perspectiva freiriana como un lugar de 'compañerismo', se fundamenta en los principios de la 'educación como práctica de la libertad'. Por tanto, valora y mantiene el diálogo permanente, la participación, la democracia, la autonomía y el compromiso ético-estético como acción política, así como la emancipación del ser humano y la transformación social para la vida sustentable.

El papel de la escuela (ciudadana), en este contexto, es contribuir para crear las condiciones que hagan viables a la ciudadanía, a través de la socializăción de la información, la discusión y la transparencia, generando una nueva mentalidad, una nueva cultura en relación con el carácter público del espacio de la ciudad.

El papel del profesor se plantea en relación con la misión que se le ha atribuido desde esta perspectiva. Es, como lo sustenta Gadotti, "transformar personas y, a su vez, ali-

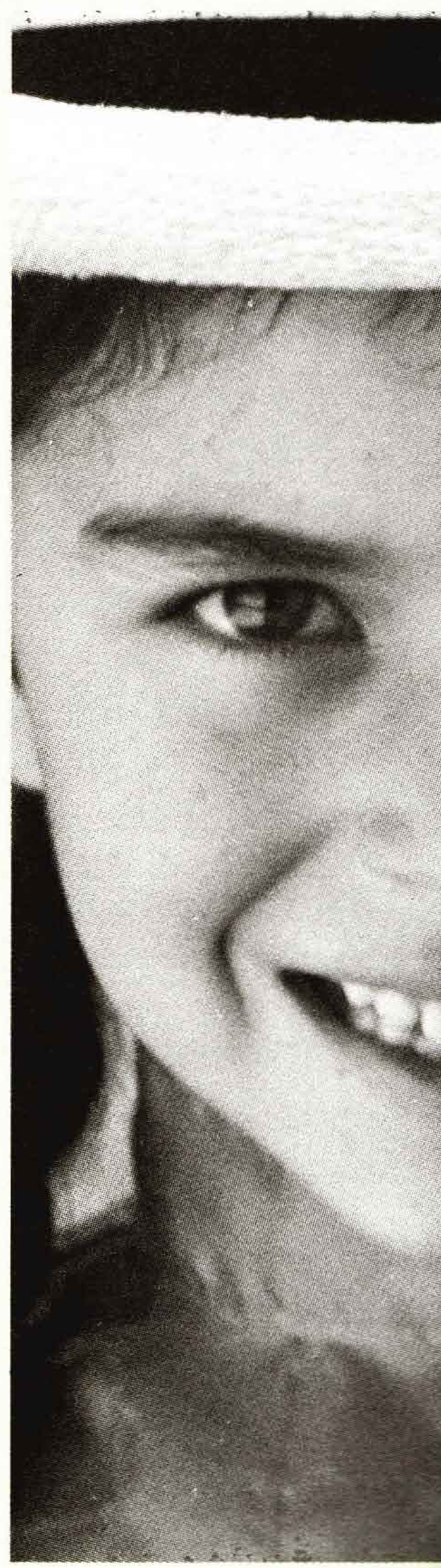


mentar su esperanza para que consigan construir una realidad diferente, una ciudad nueva, más humana, menos fea, menos malvada". Como acostumbraba decir Paulo Freire, "una educación sin esperanza, no es educación".

\section{Ciudad Educadora como" escuela del sujeto}

Entendemos esta escuela como el lugar en donde adquiere significado y se produce el interjuego entre proyectos personales y propósitos sociales; lugar en el que la educación resalta las inquietudes y problemas en torno a la existencia, la personalidad, el destino y la felicidad ${ }^{4}$ humanas.

En esta dirección, se comprende que lo educativo es resultante de un juego de poderes en el que ganan protagonismo el derecho a la diferencia y la individuación. Esta individualización significa, entre otras cosas, que la separación entre la esfera privada y la vida pública $-\mathrm{y}$, por tanto, entre la familia y la escuela- llega a su fin. La institución educativa, entonces, no podría orientarse a imponer normas a los alumnos y a transmitir a los docentes una delegación de poderes, sin otro límite que el fijado por el poder político.

\footnotetext{
4 La idea de felicidad invoca no a un estado ideal de armonía y bienestar permanente, en el cual el sujeto se pone al servicio de una causa, sino a la experiencia de reencuentro consigo mismo, en los sucesos de la propia vida y del entorno humano y material. Por ende, la felicidad no está dada, sino que se conquista, se construye.
}

De forma semejante, en una escuela del sujeto se plantea el tránsito hacia una educación que le da importancia central a la diversidad -histórica y cultural-y al reconocimiento del otro, para extenderse a todas las formas de comunicación intercultural.

Cuando se destaca la importancia de la interacción o la comunicación no se alude a un reconocimiento del Otro vía la homogeneidad, sino que se subraya la relación vía la tensionalidad, donde el reconocimiento no es propiamente el producto de una intersubjetividad comunicativa transparente y consensual, sino una interestructuración en la que profesor y estudiante, joven y adulto, se configuran en la tensionalidad tanto de la divergencia como del disenso, en tanto la dimensión interactuante en los sujetos se ve afectada y constituida por diversas, complejas y cambiantes relaciones de saberpoder.

Por tanto, nos plantea Touraine (1998), la escuela se alejará cada vez más del modelo que la concibe como agente de socializa-

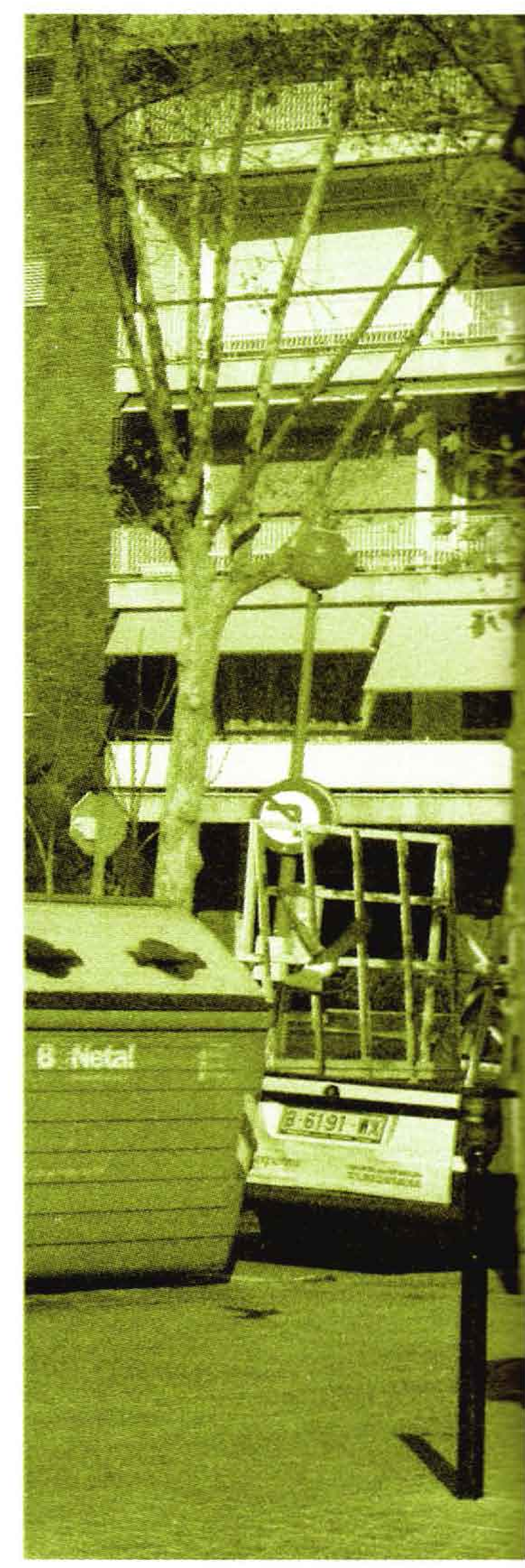


en esta dirección- y más interrelacionado, que posibilite orientaciones compartidas en los distintos proyectos y acciones que desarrolla la Secretaría.

Los maestros que acompañan este proceso cada sábado en los encuentros locales, nos ubican nuevamente en la complejidad de estos discursos que, en distintos niveles, pretenden abrir o fisurar la escuela, e incluso ignorarla. Veamos algunos de ellos.

Relacionar la escuela con la ciudad y la ciudad con la escuela no es una tarea fácil, ya que existen múltiples 'tensionalidades', entre las cuales se destaca que las directivas y coordinadores de la institución escolar no siempre están dispuestos a generar procesos de cambio, por múltiples motivos, especialmente por la centralización del poder que manejan los rectores. De igual manera, las administraciones de la Secretaría de Educación no siempre le dan un lugar central a la escuela en el proceso de construcción de ciudadanía.

La rigidez de los tiempos y espacios que tienen las instituciones hace muy difícil favorecer esta relación dinámica entre escuela y ciudad.

La cátedra de pedagogía es un sustento metodológico y teórico para que los maestros hagan lo que siempre han querido hacer. Es decir, para que asuman su autonomía y no estén atados a lo que imponen los estamentos superiores. Sin embargo, existen muchos maestros a los que no les interesa el desarrollo de una propuesta alternativa, ya que les resulta más cómodo ejecutar unas políticas ya establecidas; siendo esto un indicador de su bajo nivel de compromiso político.
Los maestros proponen análisis en torno a ciertas preguntas, para tener ejes de referencia en relación con la propuesta de Ciudad Educadora: ¿qué visión tenemos de educación, economía y desarrollo? ¿A qué modelo de desarrollo sirve la escuela? ¿Qué busca esta propuesta de Ciudad Educadora en cuanto a la construcción de ciudadanía; personas sumisas que avalen un orden establecido, o, por el contrario, crear un compromiso en las nuevas generaciones con la transformación de la ciudad y del país? ¿Formar ciudadanos hacia dónde? Esta es una pregunta central, ya que la propuesta de Ciudad Educadora está relacionada con la construcción de ciudadanía.

Se dice que se requiere una mejor educación, ¿pero al servicio de quién? ¿Cuál es la ciudad y la escuela que imaginamos, que queremos? ¿Qué hace la escuela con los imaginarios de los jóvenes? Se interrogan igualmente por los procesos de constitución de sujeto que se movilizan a través de los mass-media. Dado que el

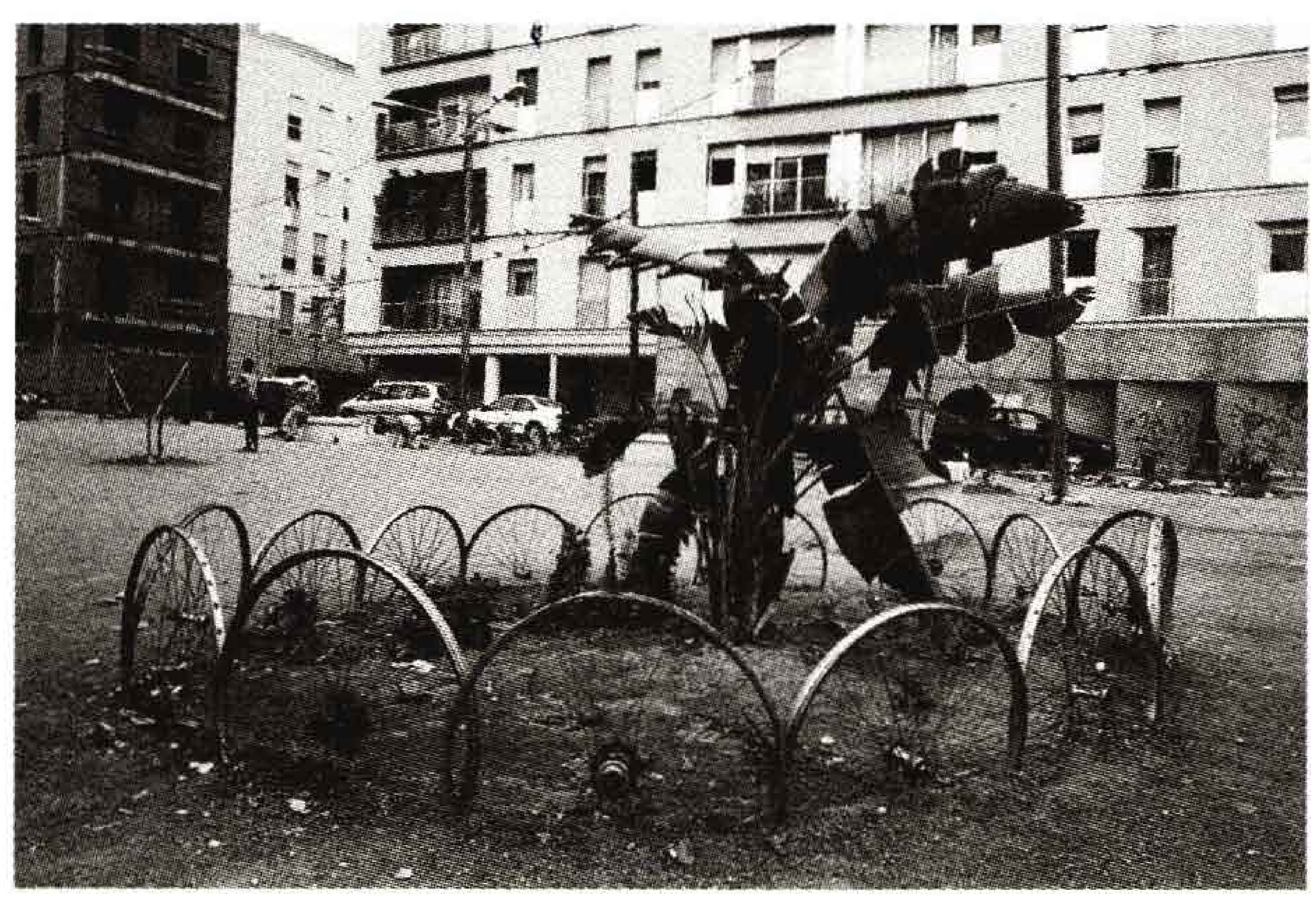




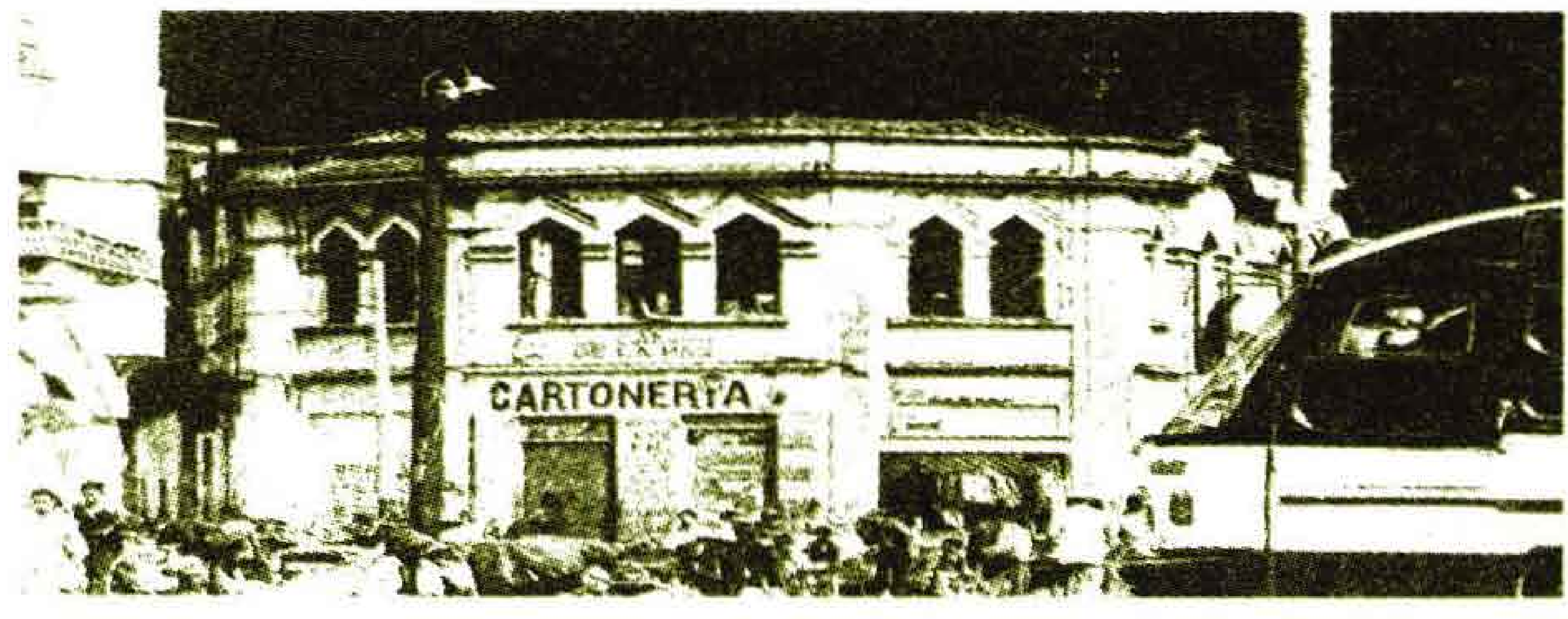

comercio constituye a los sujetos en clientes (sujetos-objetos), ¿la escuela va en una dirección semejante?

Estas son preguntas que requieren ser trabajadas, incluso para problematizar el afán intervencionista de la escuela y para repensar cómo construir oportunidades de futuro posible compartido, en los que tengan espacio tanto los jóvenes como los demás actores educativos.

En algunas de las propuestas de Ciudad Educadora, el maestro y la escuela quedan relegados y se asumen como 'un ciudadano más'.

Y aunque desde la perspectiva que se está impulsando en esta administración, se plantea un rol protagónico y central de la escuela y de los maestros en la construcción de una Ciudad Educadora, aún no es claro el tipo de participación que se busca promover por parte de los actores educativos.

La ciudad no se piensa para la diversidad de condiciones de sus ciudadanos. Y tanto el sector político como los medios de comunicación juegan un papel muy importante en estos mecanismos de exclusión.

No existen verdaderos espacios de comunicación entre los actores educativos. Muchas veces no se conocen y si se conocen no se reconocen las ideas de los maestros, ni de los estudiantes o padres de familia en la construcción de la política educativa.

La escuela de hoy es muy lenta hacia el cambio; sus estructuras son muy conservadoras, en contraste con el contexto social en el que vivimos. Vemos que los jóvenes de hoy son muy distintos a los de nuestra época, y que la escuela sigue siendo fundamentalmente la misma.

La escuela actual no está preparada para afrontar la mayoría de los conflictos que se generan al interior de ella. Ante estos nuevos retos, los maestros han reaccionado de diversas maneras. Algunos con total indiferencia, otros con una gran incertidumbre y otros con un gran compromiso, pensando que pueden afrontar los nuevos retos. Sin embargo, rápidamente se desaniman cuando se enfrentan a estructuras indiferentes con estas problemáticas.

La escuela de hoy tiene muy poco sentido para lograr una verdadera articulación con la ciudad. La descontextualización del aprendizaje está en la misma razón de ser de la institución escolar: separar el conocimiento de su ámbito pertinente, para transmitirlo de forma metódica y acelerada. Esto no quiere decir que los maestros no hagan intentos por articular el saber teórico con la práctica; pero sucede que muchas veces son intentos aislados y muy poco reconocidos.

La escuela es una institución social con sus propias peculiaridades y límites. Por ello, no se le puede dar la responsabilidad exclusiva de formar ciudadanía, ya que ésta es una responsabilidad compartida con el resto de las instituciones sociales. 
Los maestros cumplen -de manera consciente o inconsciente- con la función específica de validar un tipo de conocimiento legítimo, unas formas de comportamiento, unas determinadas maneras de hablar, vestir y hasta sentir.

Estas relaciones de poder no están sólo presentes en la relación docente-estudiante; algo muy similar sucede con los directivos docentes. Alli se ve, en muchos casos, una gran resistencia a las innovaciones educativas. Es prioridad trabajar en este aspecto, para lograr articular la escuela con la ciudad, ya que esto implica un respeto por la diversidad de pensamiento y de culturas.

Un aspecto cruciales en la construcción de una nueva escuela, que se centre en el reconocimiento de la 'multiculturalidad' y en una verdadera articulación entre escuela y ciudad, está relacionado con la formación de los maestros. $\mathrm{Al}$ respecto, surge el cuestionamiento de cómo las universidades analizan la escuela desde una perspectiva muy teórica, en la mayoría de los casos desligada de la realidad, caracterizada por su énfasis en el ideal de escuela que desconoce o pasa por alto las distintas 'tensionalidades' existentes entre docentes, estudiantes, directivas y política educativa. Así, prepara a los jóvenes para un sistema educativo que en nuestro medio no existe.

Se plantea la necesidad de revindicar el estatus que tiene el maestro en la sociedad colombiana, ya que muchos sectores se han empeñado en deslegitimar cada vez más su trabajo. Para ello, es necesario construir una dimensión real del rol del docente y de la escuela dentro de la sociedad actual, ya que cada vez se les atribuyen mayores responsabilidades, muchas de las cuales no están a su alcance.

La pérdida de legitimidad del lugar del maestro en la producción social de los saberes, tiene que ver con un concepto único acerca del mundo, la economía y la felicidad. En este contexto, el magisterio tendría que buscar la forma de articularse con otros sectores sociales, para lograr presentar su propuesta de escuela y ciudad distinta a la neoliberal, en donde se tenga como premisa la participación real -no formal- de todos los sectores que la conforman; con la consiguiente valoración de la diversidad cultural que existe en nuestro país.

Estar en camino de construir una nueva escuela implica la necesidad de que el maestro salga del currículo tradicional, caracterizado por las cuatro paredes del aula, el texto guía y las evaluaciones escritas, como vía para medir el conocimiento. Es necesario comenzar a articular el saber científico con el conocimiento populăr, e involucrar tanto a los niños como a los jóvenes y a sus padres. Esto permitirá, a su vez, construir comunidad, ya que ésta no se da 'por decreto', como algunos piensan.

Múltiples preguntas, múltiples cuestionamientos, múltiples retos que los maestros destacan y que, por fortuna para muchos de ellos, no les hace caer en la lógica del fatalismo, pero tampoco en el voluntarismo descontextualizado. Para operar con la categorización antes planteada, podemos decir que muchos maestros y algunos directivos se 'instalan' en 


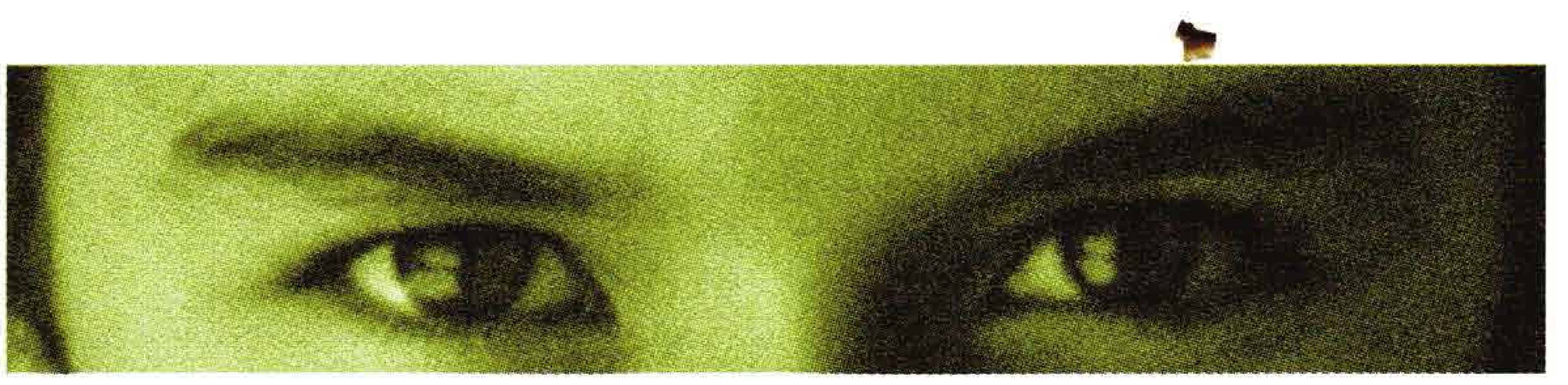

estas reflexiones y problemas bajo la perspectiva que hemos caracterizado como escuela del sujeto.

\section{La Cátedra de pedagogía Implicaciones en la formación de maestros}

En términos generales, a la cátedra se le podría atribuir el papel de incitadora o generadora de debates y de posicionamientos críticos, que favorece el diálogo con las realidades y contextos particulares y dinamiza la generación de procesos de transformación a partir de las reflexiones construidas colectivamente.

Por supuesto, la Cátedra de pedagogía tendría que incluirse dentro de una estrategia general de formación de maestros, que posibilite no sólo impulsar estas dinámicas sino además articularlas dentro de los proyectos educativos institucionales y locales y las políticas del sector educativo, tanto en el ámbito distrital como nacional. En este sentido, los entes centrales también tendrían que involucrarse en la creación de espacios y condiciones para que las iniciativas que se formulen en los contextos locales resulten viables y con posibilidades de proyección. 